\title{
A operação dramatúrgica sob a responsabilidade do encenador: «A história que eu não devia contar»
}

\author{
ANDRÉ PAES LEME
}

\begin{abstract}
This article addresses the affinity between the literary oeuvre and the dramaturgic object, focusing on the increasing presence of narrative texts in contemporary performance. We reflect upon the several motives that lead a theatre director to become artistically interested in literary material not originally written for the stage, and to identify the procedures adopted for this transposition. As an example of this kind of experience, we will go through the staging of $A$ história que eu não devia contar, by the Portuguese author João de Mancelos, staged in Lisbon (July 2016), directed by André Paes Leme, in partnership with the Cia. Falácia de Teatro.
\end{abstract}

THEATRE AND LITERATURE / LITERARY ADAPTATION / WRITING FOR THE STAGE / NARRATIVE THEATRE / THEATRE DIRECTION

Uma das principais tendências do teatro verificada desde os tempos mais remotos até aos dias de hoje é a teatralização de textos narrativos para o palco. Fábulas, contos e romances são repetidamente escolhidos por encenadores como fonte para se conceber um espectáculo de teatro. A afinidade entre a literatura narrativa e o teatro é explícita e, eu diria, embrionária e vocacional. Roger Chartier no seu estudo sobre o percurso da palavra Do Palco à Página (2002) nos revela que a escrita e a oralidade já estavam irmanadas na origem do romance literário. Jean Pierre Sarrazac (2009) nos faz lembrar que Diderot, ao criticar a impotência da dramaturgia clássica, já sugeria que o drama deveria se inspirar no romance como um modelo para a sua reforma. O mesmo Sarrazac quando aborda a questão do drama contemporâneo na sua obra O Futuro do Drama (2002) ressalta a aproximação do romance em relação ao texto teatral e pensa o novo dramaturgo como um autor-rapsodo, um parente directo do escritor do romance. No final dos anos oitenta, o encenador francês Antoine Vitez 
causa impacto quando declara que o teatro tem o direito de se relacionar com qualquer tipo de texto, «fazer teatro de tudo», inclusive, com os textos não-literários e também com os que não foram concebidos para o palco, como os romances. Essa afirmação revela uma afinidade directa com a visão de Patrice Pavis (2008) quando declara que o texto de teatro, actualmente, é tudo aquilo que se fala em cena, e Jean-Pierre Ryngaert (1998) quando se posiciona na defesa de que a escrita teatral está liberta de formatos e que o teatro actual aceita todos os textos, qualquer que seja sua origem, e que caberá à encenação a tarefa de revelar sua teatralidade. Neste caminho de reflexão cabe lembrar o provocante questionamento de Paul Zumthor (2014), pesquisador da poesia medieval, que, ao debater sobre o termo e a ideia de performance, como utilizado pelos anglo-saxões, e a sua articulação com a literatura que se transmite oralmente, chamada por Zumthor de poesia vocal, lança a pergunta: toda a «literatura» não é fundamentalmente teatro?

Neste estreito parentesco entre a literatura e o teatro, não é de se estranhar que o romance tenha alcançado no último século um status na cena teatral digno de um protagonista. Como nos lembra a pesquisadora Elena Vássina, no seu estudo sobre «Encenações das Obras Clássicas no Teatro Russo» (2011: 330), Stanislávski, em maio de 1908, disse: «Ainda não sei como, mas muito em breve, vamos encenar Dostoiévski. É impossível sem Dostoiévski.» Logo a sua previsão se confirmaria. Em 1910 é realizada a histórica montagem de Os Irmãos Karamásov, encenada por Vladímir Nemiróvitch-Dántchenko no Teatro de Arte de Moscou, que, segundo Vássina, representou um marco na arte teatral, revelando nas inter-relações com a literatura clássica uma infinita fonte de inovação.

Percorremos o século xx e, na esteira da profecia do mestre teatral russo, constatamos que importantes encenadores, como Antoine, Copeau, Baty, Barrault, Piscator, Brecht, Meyerhold, Ariane Mnouskine, Robert Wilson, Peter Brook, e tantos outros, também se aventuraram pelas páginas de uma obra de ficção literária. Como podemos verificar, assim como algumas companhias teatrais mais recentes, como, por exemplo, a portuguesa Teatromosca-que realizou uma trilogia dedicada à literatura norte-americana, levando à cena Moby Dick, de Herman Melville (2013), O Som e a Fúria, de William Faulkner (2014) e Fahrenheit 451, de Ray Bradbury (2015) - também renomados encenadores de origem lusa ou brasileira fizeram deste tipo de processo de criação um capítulo do seu percurso. Um deles é o encenador paulista Antunes Filho, nome referência do teatro brasileiro que estreou, em 1978, com o Grupo Pau Brasil, a antológica 
encenação da obra Macunaíma, do romancista Mário de Andrade. Outro encenador com destaque nesta prática é o português João Brites, que, na condução do Teatro O Bando, desde 1974, encena prioritariamente textos de origem não dramática. Entre dezenas de encenações, cabe destacar, estreado em 2004, o seu espectáculo a partir do Ensaio sobre a Cegueira, de José Saramago.

Na íntegra ou adaptada livremente, a verdade é que o palco já deve ter acolhido a obra romanesca de todas as formas imagináveis: algumas experiências mais radicais, que buscam não interferir em nenhum vocábulo da obra original e que realizam espectáculos com longas durações e, em geral, possuem forte ênfase na oralidade; outras experiências mais conservadoras que acabam por dar ao romance um acabamento dramático ao condensar e transformar toda a narrativa em diálogos, uma operação muito comum na história da dramaturgia ocidental, identificada pelo dramaturgo e encenador espanhol José Sanchis Sinisterra (2016:10) como uma operação de domesticação; e ainda outras experiências teatrais que optam pela desconstrução absoluta da fábula para que seja possível reencontrarem um sentido cénico e uma potência amplificada da narrativa visual. Nesta última perspectiva podemos lembrar, mais recentemente, o monólogo da actriz Sara Carinhas, a partir do romance Orlando, de Virginia Woolf, encenado em 2015, no Centro Cultural de Belém, em Lisboa.

Ao considerarmos essas diferentes tendências nos mais variados processos de transposição não nos parece mais pertinente tentar eleger um modelo para essa natureza de operação dramatúrgica. Serão tantos modelos quantas forem as experiências. A liberdade é total e, certamente, uma natural consequência das transformações que acompanharam, e ainda acompanham o teatro desde o fim do século XIX, que retiraram gradativamente a forma dramática do papel de pilar intocável do modelo dramatúrgico e conduziram o objecto teatral para uma necessária passagem do componente literário para o cénico, onde passaram a predominar as formas híbridas do texto teatral até chegarmos aos extremos da dramaturgia do chamado teatro pós-dramático, conforme aponta Hans-Thies Lehmann (2006).

Neste contexto, persiste a pergunta: por que encenar um romance? Um facto é certo e incontestável: um romance não foi concebido com o fim de se tornar uma obra teatral. Esta operação ocorre porque, em geral, um encenador reconhece na obra literária uma força de atracção ao palco. Seja em função da sua temática, das características das personagens ou 


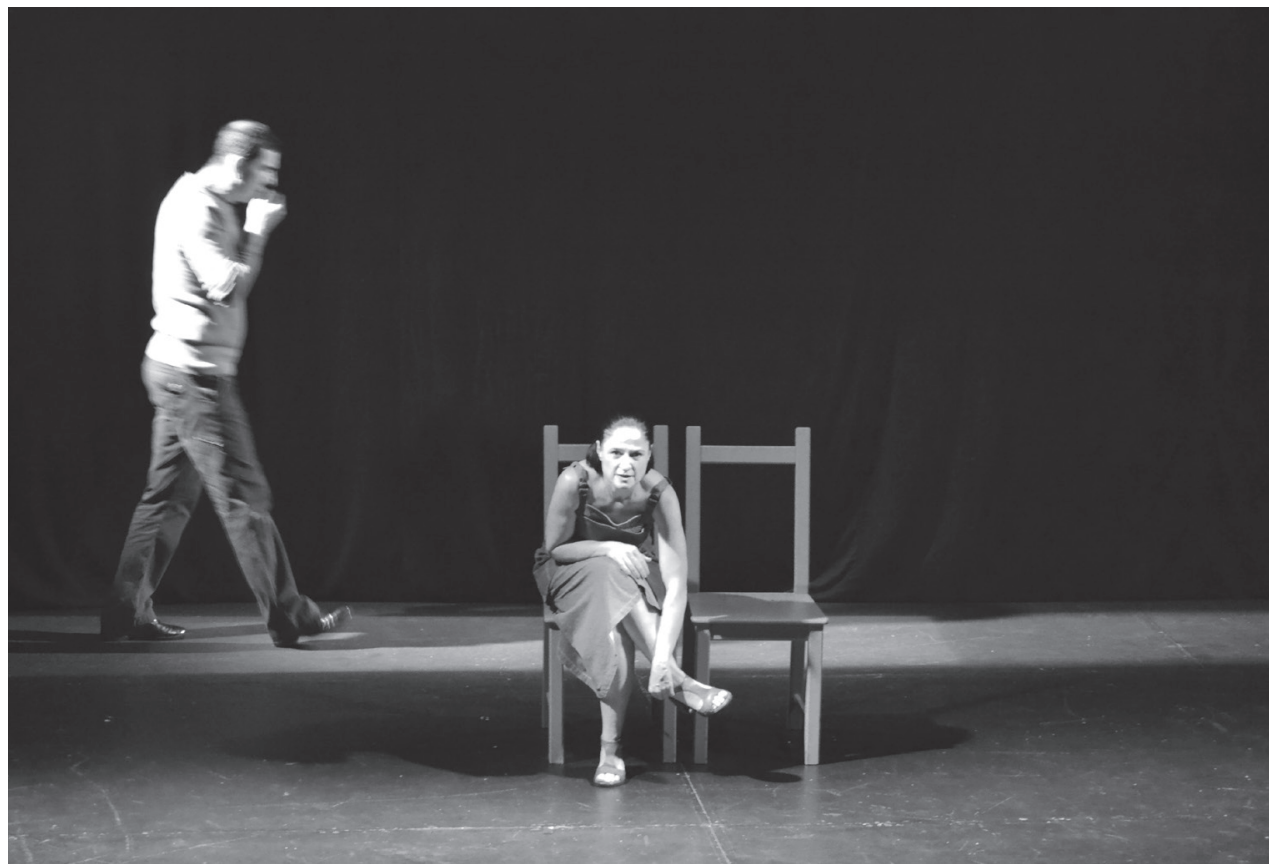

HISTÓRIAS QUE NÃO DEVIAM SER CONTADAS, ENC. ANDRÉ PAES LEME (ALEXANDRE DANTAS E CLÁUDIA VENTURA), 2016, [F] CARLA DE ABREU

do encadeamento da trama, ou qualquer outro aspecto encontrado na literatura, a verdade é que este movimento se desenvolve, exclusivamente, na mente criadora de um encenador que tem uma visão artística pessoal e identifica uma pré-disponibilidade de um determinado romance para o fenómeno teatral. O encenador reconhece naquele material inanimado, aprisionado nas páginas de um livro, uma oportunidade única para a criação de um novo material, desta vez móvel, sonoro e visual. Vale lembrar as palavras do crítico e investigador Rui Pina Coelho na sua comunicação sobre o tema em questão, intitulada $O$ palco dita, a página liberta, feita por ocasião da estreia do espectáculo Casas Pardas, uma adaptação do romance homónimo português, de Maria Velho da Costa, levada ao palco em 2012, no Teatro Nacional São João, na cidade do Porto, na qual ele elabora, sem antes deixar de insistir que teatro e literatura são obviamente áreas distintas e autónomas, uma pergunta alinhada directamente com o questionamento deste artigo: o que procura o teatro no romance? Pina Coelho intensifica um pouco mais a situação ao conjecturar se o teatro não pretende com esta aproximação ao romance superar os limites do próprio drama. 

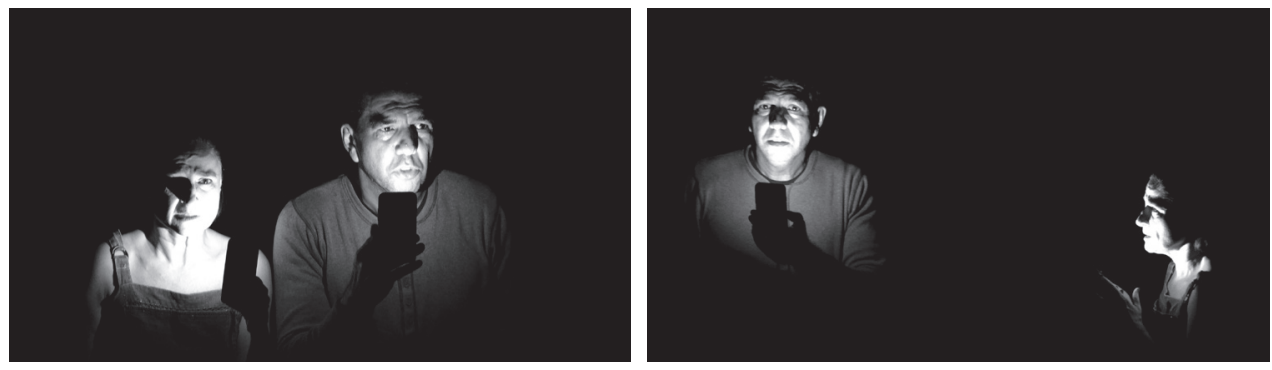

HISTÓRIAS QUE NÃO DEVIAM SER CONTADAS, ENC. ANDRÉ PAES LEME (ALEXANDRE DANTAS E CLÁUDIA VENTURA), 2016, [F] CARLA DE ABREU

Para tentarmos encontrar algumas pistas para a resposta desta questão seria importante relembrar a tese defendida pelo teórico russo Mikhail Bakhtin (1895-1975) de que o romance exerce uma influência histórica de consequências libertadoras sobre os outros géneros literários. O movimento de romanização dos géneros, segundo Bakhtin, atingiu o seu ápice no século XIX, mas a sua influência já se fazia sentida em certos períodos da Grécia antiga, da Idade Média e do Renascimento. Esta dominação pode nos fazer acreditar que a plena aproximação entre o romance e o drama era inevitável e que, talvez, até mesmo uma combinação perfeita entre os dois géneros fosse apenas uma questão de tempo, mas as transformações na escrita dramatúrgica não são tão óbvias nem tão lógicas e ainda estão fortemente implicadas com questões complexas da sociedade, sem contar as implicações da própria especificidade da arte teatral, o que torna bem mais complexa a questão.

Uma escrita que pretenda ser teatral não pode ignorar as coerções impostas pelo palco e tão-pouco esquecer que o espectáculo não será apreendido pelo acto de leitura. Haverá um actor diante do público, ou no mínimo, uma voz humana para dizer o texto determinado. Portanto, neste sentido, é mais adequado pensarmos que entre a literatura dramática e a romanesca será adequado ocorrer uma interacção recíproca das escritas, uma combinação que potencialize as duas formas e que não seja valorizado o movimento unilateral de dominação e submissão de uma pela outra.

Bakhtin ainda sobre o processo de romanização, quando faz referência ao romance de Dostoiévski (2014), ressalta que o seu carácter polifónico, plurilingue, dialógico e a sua relação com a realidade contemporânea impregnaram o género dramático. Bakhtin acrescenta ainda que, diferente do drama, a instabilidade do romance e a sua aversão a um modelo 


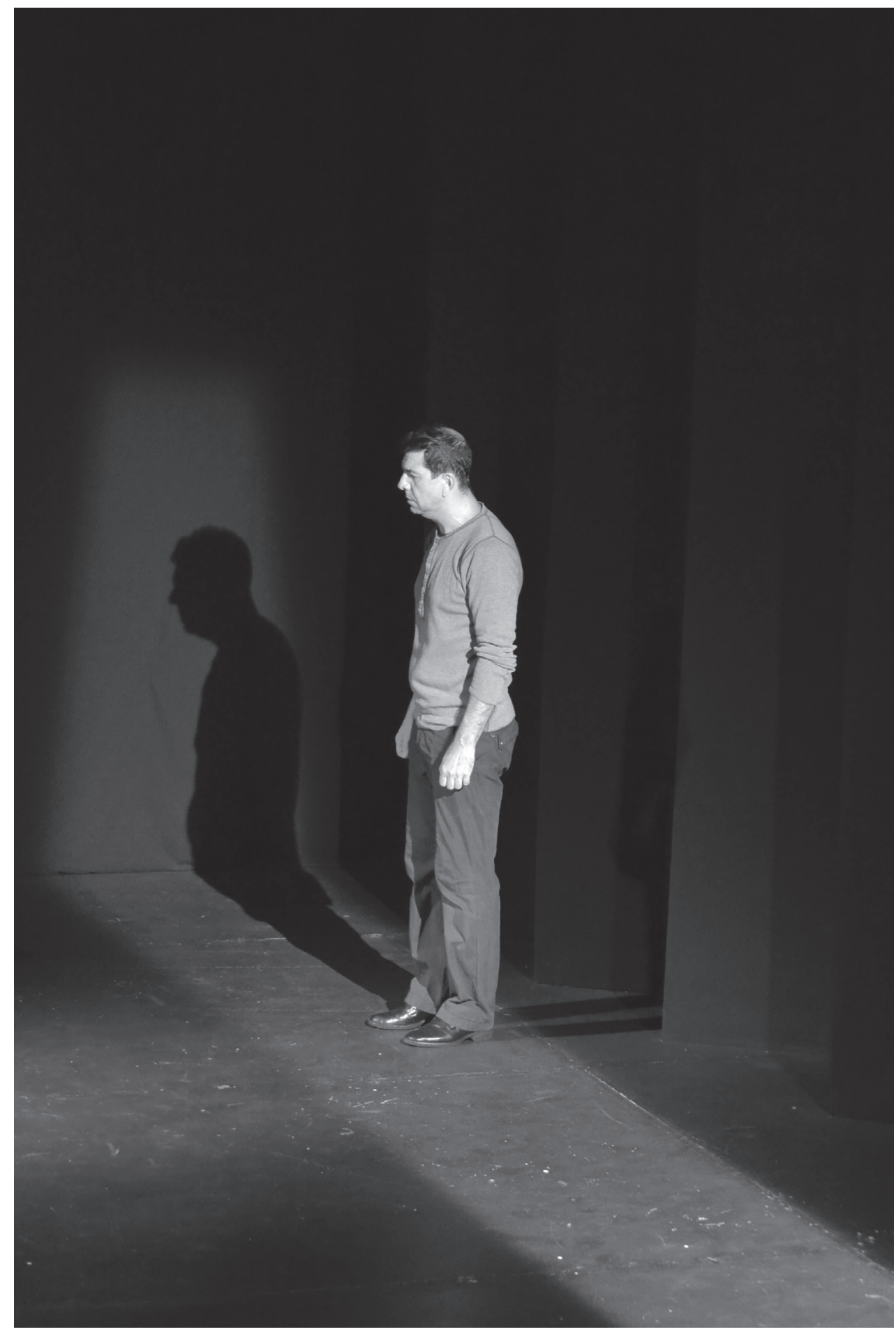

HISTÓRIAS QUE NÃO DEVIAM SER CONTADAS, ENC. ANDRÉ PAES LEME (ALEXANDRE DANTAS), 2016, [F] CARLA DE ABREU 
canónico confere ao género o seu poder libertador. Cabe também citar, em contraponto ao filósofo russo, que, por outro lado, os modelos dramáticos assumidos por alguns romancistas, como Sade e Balzac, são também responsáveis, em alguma medida, por libertarem o romance das suas próprias normas, o que fortalece, sem negar o importante papel do romance na renovação e modernização da forma dramática, a ideia acima referida de um contágio recíproco das escritas.

A força desse movimento é tamanha que seria impensável não incluir no actual processo de formação de um encenador uma análise sobre os procedimentos dessa natureza. Como se realiza a encenação de um romance? No início do meu percurso como encenador, nos anos noventa, pude assistir a marcantes trabalhos nesta linha de criação que influenciariam profundamente o meu olhar artístico, e sempre me fazia esta pergunta: começa por onde, este tipo de processo? Acostumado a ter um texto de teatro «pronto» para iniciar os ensaios, ficava a dúvida se antes de qualquer actividade com os actores eu deveria fazer uma «adaptação». Me perguntava de que forma deveria se operar esta apropriação, transposição ou transcriação, se preferirmos. Me perguntava quais seriam os limites que deveriam ser respeitados por esta «recriação», ou seria mais apropriado dizer, sem constrangimentos, criação? Me perguntava se haveria limites para esta estrutura-texto se afastar da obra original? Poderíamos, por aproximação, admitir, de acordo com as teorias do pensador russo Roman Jakobson (2001) para o conceito de tradução, que passar um texto literário para um texto encenado é antes de tudo um acto de interpretação, e que a mudança de signos que ocorre nesta operação acarreta uma transformação e, sendo assim, ocorrerá necessariamente, após a aproximação, um segundo movimento de afastamento do texto original? Ou seria ainda mais apropriado buscar apoio na noção de desleitura do crítico norte-americano Harold Bloom (1995) e entender que todo procedimento deve ser, para o bem da inventividade artística, um desvio do texto literário?

Habitado por tantas questões, nos últimos anos acumulei pequenas experiências com a teatralização de textos narrativos e uma delas, por sinal, vivenciada recentemente.

Em Abril de 2015 iniciei, em parceria com a Cia. Falácia de Teatro ${ }^{1}$, uma pesquisa de contos de origem lusa e brasileira para a criação de

1 Companhia sediada no Rio de Janeiro que desde a sua constituição, em 2008, realiza espectáculos originados em textos narrativos. O primeiro foi $A$ Nova Ordem das Coisas, baseado no conto A Igreja do Diabo, de Machado de Assis, e o segundo foi Amor Confesso, uma reunião de contos do autor Arthur Azevedo. 


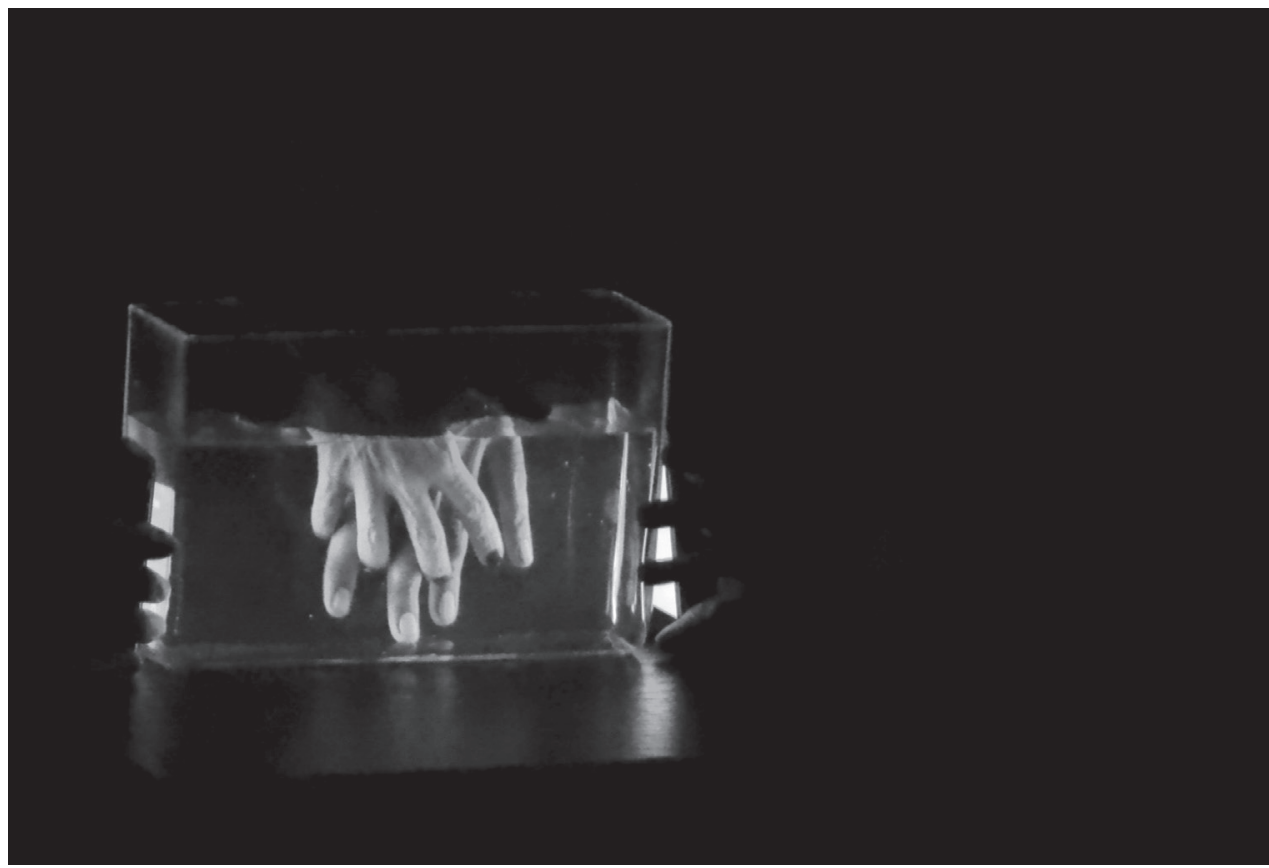

HISTÓRIAS QUE NÃO DEVIAM SER CONTADAS, ENC. ANDRÉ PAES LEME (ALEXANDRE DANTAS), 2016, [F] CARLA DE ABREU

um espectáculo. Estávamos interessados em histórias de pessoas em situações extremas. Foram seleccionadas quatro obras, duas do autor brasileiro Rubem Fonseca, «O Outro» e «O Buraco na PAREDE», e duas do autor português João de Mancelos $^{2}$, «O que sentes quando a chuva cai?» e «A história que eu não devia contar». Esta última obra, que é objecto de apreciação desse artigo, foi a inspiração para o título do espectáculo - Histórias que não deviam ser contadas - que foi apresentado no teatro Passagem de Nível, localizado na Amadora, e na Tenda do Chapitô, em Lisboa, em julho de 2016.

«A história que eu não devia contar» relata a paixão de um casal de gémeos. Alberto e Catarina vivem um amor proibido que, com a chegada da adolescência, fica cada vez mais intenso e devastador. Os irmãos, flagrados na escola e não suportando mais o segredo, decidem que apenas o assassinato dos pais poderá afastá-los definitivamente. Numa noite, na mesma cama em que foram gerados, matam os pais a facadas. 
A narrativa é feita através da personagem de Alberto, dez anos depois da morte dos pais, e é entrecortado pelos diálogos entre os irmãos:

- O nosso segredo, mano. Nunca o contaremos.

- Nunca - assentia.

No entanto, com o tempo, em vez de brincarmos às escondidas, começámos a revelar alguns indícios da paixão. Só uma década depois percebi que essa necessidade se fundamentava no desejo de reconhecimento do nosso pecado. (Mancelos, 2006: 76)

Inicio por estas duas informações, quem narra e quando narra, porque estes foram exactamente os dois aspectos que já nos primeiros ensaios definimos que seriam modificados. Ficou estabelecido que a narrativa seria dividida entre os dois irmãos e que seria localizada temporalmente próxima do assassinato, ou seja, as personagens ainda seriam adolescentes. Apesar dessa mudança, o desejo era interferir o menos possível na narrativa de Mancelos. Inicialmente estava descartada a ideia de cortes profundos e acréscimos extratextuais ao original, partimos apenas do interesse em redistribuir os textos pelas duas personagens. É importante ressaltar que estas escolhas nasceram nos ensaios, já na leitura em voz alta do conto e na ocupação de uma área cénica determinada, ainda que este espaço não representasse nenhum ambiente determinado no texto, portanto, nenhuma dessas ideias foram decididas individualmente pelo encenador antes dos ensaios. No espaço deixamos apenas duas cadeiras e os atores tinham total liberdade para se movimentarem. Foi neste árido palco que ficou evidente que a escolha de distribuir o protagonismo da narrativa entre as personagens era acertada. Evitava que a actriz ficasse continuadamente numa situação de espera e retirava uma certa secundariedade da sua participação no assassinato. Ela deixava de ser cúmplice para também ser autora.

Divididas as narrativas entre os actores e realizado um pequeno acerto em relação ao género do detentor da fala, partimos naturalmente para uma fase de memorização e de estipulação da movimentação cénica. Foi aí que percebemos que havia uma interessante possibilidade de separarmos e distinguirmos ainda mais as duas personagens. Entendemos que simplesmente dividir as narrativas entre os dois actores não era o suficiente para a dualidade da acção ganhar força. As personagens ainda pareciam ser uma única pessoa pois compartilhavam o mesmo lugar, o mesmo tempo, narravam sobre a mesma situação e numa mesma linha 


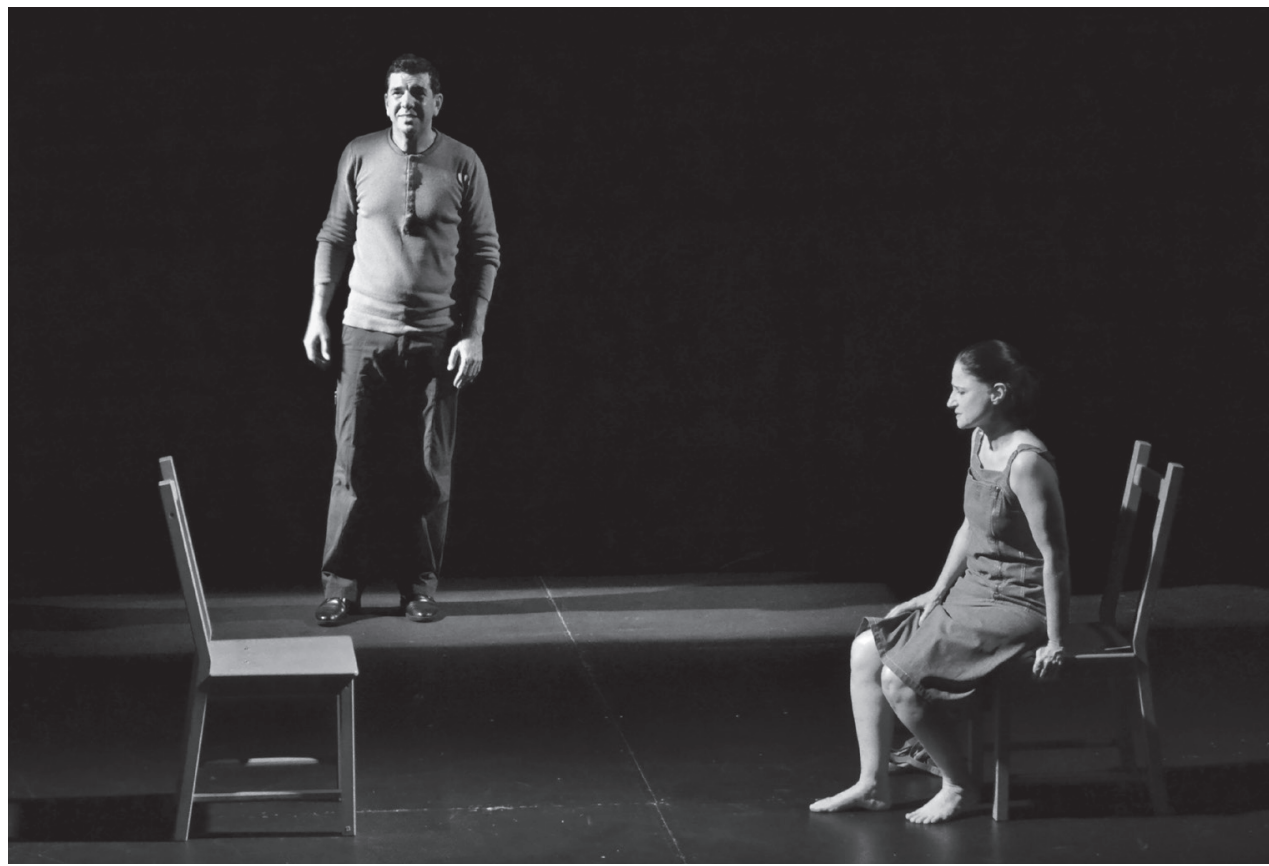

HISTÓRIAS QUE NÃO DEVIAM SER CONTADAS, ENC. ANDRÉ PAES LEME (ALEXANDRE DANTAS E CLÁUDIA VENTURA), 2016, [F] CARLA DE ABREU

cronológica dos factos, ou seja, só alternavam a fala. Para alterar esse quadro, experimentámos deslocar no tempo a narrativa da personagem feminina e assumir que o relato das duas personagens aconteceu muito tempo depois do assassinato. A irmã iniciaria a sua narrativa do final do relato da noite do assassinato e, através das suas lembranças, retornaria no tempo reconstituindo o crime. Já o irmão seguiria a cronologia original, iria das lembranças da infância até a noite do crime. Dessa forma, as personagens já não se encontravam no mesmo espaço e tempo e também não narravam as lembranças na mesma cronologia. Eram dois depoimentos distintos que se cruzavam nas cenas em que ambos convocavam, através da memória, a presença do outro. Eram três tempos diferentes convivendo no palco, o de cada irmão e o da intersecção de suas memórias. As palavras que finalizam o conto, na voz da irmã, foram antecipadas para o início de tudo e repetidas novamente pelo irmão no final de toda a cena. Verificamos que a repetição de algumas partes do texto elucidava para o espectador que se tratava da mesma situação. Estava nítido que estávamos diante de dois monólogos sobre o mesmo facto. Como os actores não contracenavam durante os monólogos, a aproximação física deles 
no espaço contribuía para revelar que eles não estavam nem no mesmo lugar nem no mesmo tempo ficcional. Fisicamente próximos, mas distantes no tempo. A partir desta configuração, percebemos que alargamos as possibilidades da cena e ganhamos mais liberdade na ocupação do palco. Uma tensão mais constante entre as personagens foi verificada. Manipulamos com mais propriedade o tempo e o espaço verificado na cena, ficamos mais livres da acção verbal. As personagens ganharam mais autonomia, como se a cena pudesse prescindir de uma das personagens. Tenho a impressão de que o que alcançamos foi consequência de um olhar que partiu da materialidade da cena e não exclusivamente do texto. Seria esta a forma de um encenador operar a dramaturgia? Priorizar sempre a materialidade da cena? Esta experiência parece fortalecer a minha impressão de que a matéria-prima do encenador se revela no espaço vazio do palco, nos corpos vivos dos actores e no tempo que abraça aquele facto cénico. Certamente outros exercícios virão para que eu possa compreender com mais nitidez o que exactamente a prática do encenador exige quando se pretende operar uma transformação dramatúrgica.

\section{REFERÊNCIAS BIBLIOGRÁFICAS}

вакнтіn, Mikhail (2014), Questões de Literatura e de Estética (A Teoria do Romance), trad. Aurora Fornoni Bernardini et al., São Paulo, UNESP/Hucitec.

BLоом, Harold (1995), Um Mapa da Desleitura, trad. Thelma Médici Nóbrega, Rio de Janeiro, Imago.

BRITES, João (2009), Iluminar a Palavra para a Revelar em Cena (texto apresentado no colóquio internacional Percursos de genética teatral: do laboratório de escrita à cena, organizado pelo Centro de Estudos de Teatro da Universidade de Lisboa).

CHARTIER, Roger (2002), Do Palco à Página: publicar teatro e ler romances na época moderna (séculos XVI-XVIII), trad. Bruno Feitler, Rio de Janeiro, Casa da Palavra.

COELHO, Rui Pina (2012), «O palco dita, a palavra liberta: algumas notas sobre adaptação de romance para cena [a propósito de Casas Pardas]», https://maiscritica.wordpress.com/2013/o1/29/o-palco-dita-a-paginaliberta-algumas-notas-sobre-adaptacao-de-romances-para-cena-a-proposito-de-casas-pardas/.

DIAs, Juarez Guimarães (2015), Narrativas em Cena: Aderbal Freire Filho (Brasil) e João Brites (Portugal), Rio de Janeiro, Móbile Editorial.

FONSECA, Rubem (2007), Feliz Ano Novo, São Paulo, Companhia das Letras.

- (2001), O Buraco na Parede, Rio de Janeiro, Nova Fronteira.

JAKo BSON, Roman (2001), Linguística e Comunicação, trad. Isisdoro Blikstein e José Paulo Pães, São Paulo, Cultrix. Lehmann, Hans-Thies (2007), Teatro Pós-Dramático, trad. Pedro Süssekind, São Paulo, Cosac Naify. (ed. port. Teatro Pós-Dramático, Orfeu Negro, 2017).

MANCELOS, João de (2006), A história que eu não devia contar/The Story I Shouldn't Tell, trad. John Elliott, Onde a Terra Acaba: Contos Portugueses/From the Edge: Portuguese Short Stories, Lisboa, CEAUL/101 Noites, pp. $75-83,78-86$.

NUNES, Luis Arthur (200o), «Do livro para o palco: formas de interacção entre o épico literário e o teatral», $O$ Percevejo - Revista de teatro, crítica e estética, 8 (9), Rio de Janeiro, UNIRIO. 
PAVIS, Patrice (2008), «Do texto ao palco: um parto difícil», in O Teatro no Cruzamento de Culturas, trad. Nanci Fernandes, São Paulo, Perspectiva, pp. 21-42.

RYNGAERT, Jean-Pierre (1998), Ler o teatro contemporâneo, trad. Andréa Stahel M. da Silva, São Paulo, Martins Fontes.

SARRAZAC, Jean Pierre (2002), O Futuro do Drama: Escritas dramáticas contemporâneas, Porto, Campo das Letras. - (2009), «A irrupção do romance no teatro», Revista Folhetim, trad. Fátima Saadi, Rio de Janeiro, Teatro do Pequeno Gesto, n. ${ }^{\circ} 28$, pp. 7-15.

Sin ISTE RRA, José Sanchis (2016), Da Literatura ao Palco: Dramaturgia de textosnarrativos, São Paulo, É Realizações Editora.

VÁssinA, Elena (2011), «Encenações das Obras Clássicas no Teatro Russo», Teatro Russo: literatura e espetáculo, org. Arlete Cavaliere \& Elena Vássina, São Paulo, Ateliê Editorial, pp. 329-42.

vitez, Antoine (1991), Le Théâtre des Idées, antologia por Danièle Sallenave e Georges Banu, Paris, Gallimard.

zumthor, Paul (2014), Performance, Recepção, Leitura, trad. Jerusa Pires Ferreira e Suely Fenerich, São Paulo, Cosac Naify.

\section{ANDRÉ PAES LEME}

André Paes Leme é encenador e professor da Escola de Teatro da Universidade Federal do Estado do Rio de Janeiro - UNIRIO. Doutorando em Estudos de Teatro na Faculdade de Letras da Universidade de Lisboa. 